\title{
Prediction of Vertebral Fractures by Trabecular Bone Score in Patients With Ankylosing Spondylitis
}

\author{
Zdenko KILLINGER ${ }^{1}$, Martin KUŽMA ${ }^{1}$, Soňa TOMKOVÁ ${ }^{2}$, Kristína BRÁZDILOVÁ ${ }^{1}$, \\ Peter JACKULIAK ${ }^{1}$, Juraj PAYER ${ }^{1}$
}

${ }^{1} 5^{\text {th }}$ department of Internal Medicine, Comenius University Faculty of Medicine, University hospital, Bratislava, Slovakia, ${ }^{2}$ Internal department of Private Hospital, Šaca-Košice, Slovakia

Received February 23, 2021

Accepted August 8, 2021

\begin{abstract}
Summary
Ankylosing spondylarthritis (AS) is associated falsely increased lumbar spine bone mineral density (BMD). New tool for discrimination of subjects at fracture risk is needed. Vertebral fracture (VF) prediction of routine methods for osteoporosis assessment, BMD and trabecular bone score (TBS), in patients with AS. Cross-sectional study of all AS patients regularly followed at the rheumatology outpatient clinics of two centers. All subjects undergone BMD measurement at lumbar spine (LS), total hip (TH) and femoral neck (FN) using Hologic $₫$ Horizon device. TBS at L1-4 in all subjects by TBS InSight $\AA$ software were assessed. Vertebral fracture assessment (VFA) was performed using the lateral spine imaging IVA ${ }^{\mathrm{TM}}$ and graded using Genant semi-quantitative approach. 119 AS subjects (90 males/29 females), mean age 47.6 years were included in the study. In 20 patients $34 \mathrm{VFs}$ were detected, from whom 7 patients had multiple fractures. Subjects with VF were older and had lower FN BMD, TBS in comparison to non-VF subjects. No differences in LS BMD, FN BMD or BASDAI between groups were observed. Among patients with VF only 3 had T-score less than -2.5 but 7 has TBS less than 1.23 which means highly degraded microarchitecture. AS patients with VF have lower TBS and FN BMD in comparison to non-VF subjects. In addition, TBS was able to detect $20 \%$ more VFs than BMD. Therefore, TBS seems promising in VF discrimination among patients with AS.
\end{abstract}

\section{Key words}

Trabecular bone score • Vertebral fractures • Ankylosing spondylitis

\section{Corresponding author}

Martin Kužma, $5^{\text {th }}$ department of Internal Medicine, Comenius University Faculty of Medicine, University Hospital Bratislava, Ružinovská 6, 82606 Bratislava, Slovakia. Email: martin.kuzma@fmed.uniba.sk

\section{Introduction}

Bone mineral density (BMD) in primary postmenopausal and senile osteoporosis is associated with fracture risk. Nevertheless, in secondary osteoporosis, including inflammatory rheumatic diseases, BMD is not sufficient as the discriminant tool for fragility fractures. Thus, other factors and bone measures has to be considered. Ankylosing spondylitis (AS) is a chronic inflammatory rheumatic disease of the axial skeleton. Typical radiological features are sacroilitis and bridging syndesmophytes of the spine. Pathologic new bone formation in the cortical bone of the vertebrae and impairment and loss of trabecular bone mass of the vertebral body leading to osteoporosis and prevalent 2- to 8 -fold higher vertebral fractures (VF) risk in comparison to healthy subjects (Cooper et al. 1994, Vosse et al. 2009, Muñoz-Ortego et al. 2014). Prevalence of radiographic vertebral fractures is ranging from $10 \%$ to $43 \%$ (Donnelly et al. 1994, Mitra et al. 2000, Lange et al. 2005, Jun et al. 2006, Vosse et al. 2006, Ghozlani et al. 2009, Arends et al. 2011, MONTALA et al. 2011, Klingberg et al. 2012, Kang et al. 2014, Ulu et al. 2014, Kilic and Ozgocmen 2015). Due to relatively young and predominantly male population of patients frequently suffering from AS neither the patient nor the physician is aware of this increased risk. Moreover, several difficulties in the fracture risk assessment such as falsely increased lumbar spine BMD caused by ligamentous ossification or alterations of bone quality due to chronic inflammation may contribute to delay in prevention or treatment of this serious condition. Thus appropriate bone 
measure, reflecting bone strength, microstructure and presence of ossifications, to predict future fracture and to initiate treatment in routine practice is needed.

HR-pQCT and Micro CT are helpful in assessment of bone microstructure but due to their availability and cost, these methods are at this time not used in routine clinical practice. On the other side, lumbar spine trabecular bone score (TBS) is easy to obtain from existing DXA scans of lumbar spine and therefore suitable for use in routine manner. TBS represents a bone texture parameter, reflecting degradation of trabecular bone. It could bring additional information about the risk of fragility fractures in conditions where BMD is less effective, e.g. secondary osteoporosis. This, particularly was observed in diabetes mellitus (Leslie et al. 2013, Jackuliak and Payer 2014), rheumatoid arthritis (Killinger et al. 2019), endogenous hyperthyroidism in pre-menopausal women (Kuzma et al. 2018), acromegaly (Kužma et al. 2019) or glucocorticoidinduced osteoporosis (Leib and Winzenrieth 2016).

This cross-sectional study is aimed to compare routine methods for osteoporosis assessment, BMD and TBS, in patients with AS with regards to occurrence of VFs.

\section{Patients and methods}

This cross-sectional study two rheumatology centers (Bratislava, Košice) study of AS patients was conducted from January 2018 to January 2019. The study protocol was reviewed and approved by Comenius University Faculty of Medicine research boards. The regional medical ethics committee approved the study. All patients regularly followed at the rheumatology outpatient clinics who met inclusion criteria were included in the study; signed informed consent was obtained prior to the conduct of any study procedure.

\section{Inclusion criteria}

Study group consisted from AS patients regardless age, gender, disease duration, activity who came for follow-up visit during study inclusion period.

\section{Exclusion criteria}

Subjects with corticosteroid or osteoporosis treatment, except calcium and vitamin D supplementation, were not included in the study.

In total, one hundred nineteen patients, 90 of whom were males and 29 females (11 postmenopausal) with mean age 47.6 years with AS, were included in the study. Fifty-two patients were on biologics (TNF alfa ihibitors - adalimumab, etanercept, golimumab).

\section{Methods}

Basic anthropmetric characteristics, such as age, height, weight and body mass index (BMI) were assessed in all subjects. The mean diseases duration was 18 years and mean BASDAI (Bath Ankylosing Spondylitis Disease Activity Index) index was 3.7. BASDAI consists of a 0-10 scale measuring discomfort, pain, and fatigue ( 0 being no problem and 10 being the worst problem) in response to six questions asked of the patient pertaining to the five major symptoms of AS (Garrett et al. 1994).

In all subjects a single measurement of BMD was performed. BMD measurements at the L1-4 spine (LS), femoral neck (FN) and total hip (TH) were performed using DXA with a Hologic Horizon device with APEX software version 13.3:7. For premenopausal women and men under 50 years Z- score was used for classification of osteoporosis. For everybody else T-score was used. For definitive analysis of differences between groups BMD in $\mathrm{g} / \mathrm{cm}^{2}$ was used. Quality control was performed by daily calibration using the Hologic crosscalibration phantom. The scans were acquired and analysis was performed by the same one technologist at each place. TBS was performed from lumbar spine DXA scans using TBS iNsight ${ }^{\circledR}$ software (Medimaps SASU, Pessac, France) version 3.0.2.0. Coefficient of variation of the TBS was less than $1 \%$. Vertebral fracture assessment (VFA) was performed using the lateral spine imaging IVA $^{\mathrm{TM}}$ mode with a Hologic Horizon ${ }^{\circledR}$ A densitometer (Hologic Inc., Marlborough, MA). IVA has the same validity as X-ray but has greater potential for daily clinical use due to its speed, small radiation and option to perform all bone examinations on same machine at one single place.

Two lateral scans were performed in the supine position; one with single-energy and a second with dualenergy to ensure the best possible image quality. Each vertebra was assessed using the Genant semiquantitative scoring method (Genant et al. 1996), grading as normal or mild, moderate, or severe fracture.

\section{Laboratory assessment}

Serum total procollagen type $1 \mathrm{~N}$-terminal propeptide (P1NP) and C-terminal telopeptide (CTx) levels were assessed by ECLIA using a Roche Elecsys 1010/2010. P1NP values are expressed as $\mu \mathrm{g} / 1$ with inter- 
assay precision between 2.3-3.7\%. CTx values are expressed as $\mathrm{pg} / \mathrm{ml}$ with inter-assays precision of 1.6-4.7\%. Blood sampling was performed not later than 14 days after the inclusion in the study.

\section{Statistical analysis}

Statistical analysis was performed using the statistics software Analyse-it (Leeds, United Kingdom) v 5.40.2. Continuous data were expressed as the mean \pm standard deviation (SD). Before statistical analysis we have performed screening for outliers defined as values greater than +3 SDs or lower than -3SDS for each variable, who were excluded from the study. The Shapiro-Francia test was used to test the normality of the distributions of studied parameter. Inter-group comparisons were performed using either a Student's t-tests or Mann-Whitney tests, depending upon the normality distribution of the studied parameter. For bonerelated measurements ANCOVA analysis was used to performed Inter-group comparisons considering all other significant discriminant parameters as covariate. For the statistical significance a level $\mathrm{p} \leq 0.05$ was used.

\section{Results}

Postmenopausal females has average T-score:
$-0.7 ;-1.2$ and -0.6 at LS, neck and TH, respectively. Males over 50 years $(\mathrm{N}=34)$ had average $\mathrm{T}$-score 0.17 ; -1.08 and -0.56 at LS, neck and $\mathrm{TH}$, respectively. Five subjects had T-score less than -2.5. Premenopasual females had average Z-score $0.4 ;-0.1$ and -0.1 at at LS, neck and TH, respectively. Males under 50 years had Z-score $-0.5 ;-0.52$ and -0.15 at LS, neck and $\mathrm{TH}$, respectively. Six subjects had Z-score less than -2.0. There were no significant differences in bone measures among patients on biologics $(\mathrm{N}=52)$ in comparison to patients without biologic treatment.

In the further analysis, males had greater weight, height and TH BMD in comparison to females (Table 1). All other differences were not statistically significant. In $20(16.8 \%)$ patients (18 males/2 females) totally $34 \mathrm{VFs}$ were detected. In 7 patients with VF (6 males/1 female), multiple fractures were observed. Most frequent were mild wedge-shaped or biconcave fractures (13 patients) and moderate (grade II) wedge-shaped fractures (7 patients). From VF subjects, $3 ; 1 ; 7 ; 13$ subjects has T-score $\leq-2.5 ;$ Z-score $\leq-2.0, \mathrm{TBS} \leq 1.23$ and TBS $\leq 1.31$, respectively. Subjects with VF were older and had lower age-adjusted FN BMD and TBS (Fig. 1) in comparison to non-VF subjects (see also Table 1). No differences in age-adjusted LS BMD, FN BMD or BASDAI were observed.

Table 1. Comparisons between study groups.

\begin{tabular}{|c|c|c|c|c|c|c|}
\hline Parameter (unit) & Male $(\mathbf{N}=90)$ & $\begin{array}{c}\text { Female } \\
(\mathrm{N}=29)\end{array}$ & p value & $\begin{array}{l}\text { With VF } \\
(\mathbf{N}=\mathbf{2 0})\end{array}$ & $\begin{array}{l}\text { Without VF } \\
\qquad(\mathrm{N}=92)\end{array}$ & p value \\
\hline Age (years) & $47.6 \pm 11.7$ & $47.9 \pm 11.7$ & NS & $54.8 \pm 11.4$ & $46.3 \pm 11.3$ & 0.003 \\
\hline Weight (kg) & $87.5 \pm 13.64$ & $74.54 \pm 17.5$ & $<0.0001$ & $89.4 \pm 13.4$ & $83.5 \pm 15.9$ & NS \\
\hline Height $(\mathrm{cm})$ & $176.4 \pm 7.4$ & $163.4 \pm 6.2$ & $<0.0001$ & $175 \pm 8.7$ & $172.6 \pm 9.2$ & NS \\
\hline$B M I\left(\mathrm{~kg} / \mathrm{m}^{2}\right)$ & $28.1 \pm 4.1$ & $27.9 \pm 6.6$ & NS & $29.1 \pm 3.7$ & $27.9 \pm 5$ & NS \\
\hline$L S B M D\left(\mathrm{~g} / \mathrm{cm}^{2}\right)$ & $1.057 \pm 0.15$ & $1.021 \pm 0.14$ & NS & $1.053 \pm 0.17$ & $1.043 \pm 0.15$ & NS \\
\hline$F N B M D\left(\mathrm{~g} / \mathrm{cm}^{2}\right)$ & $0.747 \pm 0.15$ & $0.755 \pm 0.12$ & NS & $0.677 \pm 0.16$ & $0.766 \pm 0.14$ & 0.01 \\
\hline$T H B M D\left(\mathrm{~g} / \mathrm{cm}^{2}\right)$ & $0.983 \pm 0.13$ & $0.906 \pm 0.11$ & 0.005 & $0.933 \pm 0.13$ & $0.971 \pm 0.13$ & NS \\
\hline$T B S$ & $1.336 \pm 0.11$ & $1.368 \pm 0.12$ & NS & $1.247 \pm 0.10$ & $1.359 \pm 0.11$ & $<0.0001$ \\
\hline$B A S D A I$ & $3.81 \pm 2.2$ & $3.84 \pm 2.1$ & NS & $3.4 \pm 2.12$ & $3.8 \pm 2.2$ & NS \\
\hline$s-C T x(n g / l)$ & $363.9 \pm 133$ & $453.9 \pm 266$ & NS & $297.5 \pm 114$ & $408.4 \pm 163$ & 0.03 \\
\hline$s-P 1 N P(u g / l)$ & $47.9 \pm 18.1$ & $45.3 \pm 17.4$ & NS & $40.3 \pm 21.9$ & $45.6 \pm 18.8$ & NS \\
\hline$s-A L P($ ukat/l) & $1.19 \pm 0.3$ & $1.17 \pm 0.35$ & NS & $1.14 \pm 0.3$ & $1.2 \pm 0.3$ & NS \\
\hline Smoking N (\%) & $10(11.1)$ & $6(6.6)$ & NS & $4(20)$ & $12(13.4)$ & NS \\
\hline Alcohol N (\%) & $5(5.5)$ & $1(1.1)$ & 0.001 & 0 & $6(6.5)$ & NS \\
\hline
\end{tabular}





Fig. 1. Differences in bone measures; $L S, T H, F N$ BMD and TBS among patients with VF in comparison to non-VF subjects. 


\section{Discussion}

VFs are an important and not rare complication of longstanding AS however, usually most of them remain unrecognized. There is still undergoing discussion about the clinical significance of mild fractures, although several studies have shown that the presence of mild fractures is associated with an increased risk of developing new vertebral fractures (Delmas et al. 2003, Klingberg et al. 2013).

This study shows that AS patients with VF have lower TBS and FN BMD in comparison to non-VF subjects. Among patients with VF only 3 had T-score less than -2.5 but 7 has TBS less than 1.23 which means highly degraded microarchitecture. Taken altogether TBS was able to detect $20 \%$ more VFs.

Detection of patient suffering from AS, with increased risk of fracture may have in routine practice several limitations. Decreased bone mineral density is although a common complication in AS patients but overestimation of BMD due to presence of syndesmophytes may lead to false negative results. Especially in patient with long term duration of the disease, the risk of the fracture may be increased and masked by overall satisfactory BMD value due to ligamentous ossifications. Insufficient reflection of the impaired quality of trabecular bone due to chronic inflammation may be another factor why measurement of BMD cannot sufficiently predict fracture risk. Thus BMD is useful tool in fracture risk prediction in postmenopausal and senile osteoporosis, but in secondary osteoporosis, such as glucocorticoid induced osteoporosis (Leib and Winzenrieth 2016), diabetes mellitus (Leslie et al. 2013, Jackuliak and Payer 2014) including AS (Kang et al. 2018a), BMD is often not associated with fracture risk.

In patients with advanced syndesmophytes in the lumbar spine, region measurement of the hip or lateral projection of spine may be used. Although spinal DXA using a lateral view has the advantage of allowing selection of a trabecular zone in the center of the vertebral bodies, it has poor precision due to the difficulty in positioning the patients (Vosse et al. 2006). Hip BMD in this young male population falls despite possible small decreases in BMD frequently in osteopenia and thus cannot be used as treatment threshold in routine practice. In this study, BMD at femoral neck in VF subjects were significantly lower in comparison to non-VF subjects. Nevertheless, only four patients were classified as osteoporotic based on BMD criteria.

HR-pQCT is able to distinguish between cortical and trabecular bone and thus in advanced AS, HR-pQCT more frequently detects low spine BMD than DXA (Devogelaer et al. 1992, Karberg et al. 2005). However, due to high radiation dose, cost and limited access, HR-pQCT can't be performed routinely. According to EULAR recommendations, AS patients with syndesmophytes at lumbar spine, diagnosis of osteoporosis should be established by hip BMD, supplemented by spine BMD in lateral projection or possibly quantitative CT (QCT) of the spine (Mandl et al. 2015). Therefore, a simple non-invasive tool that is unaffected by spinal ossifications reflecting bone quality is needed to assess bone changes and to predict fracture risk in AS. This problem, at least partially could be solved by TBS. TBS may be useful to identify future fracture risk in patients with AS.

Our findings indicate that low TBS is able to distinguish between VF and non-VF subjects. Accordingly, TBS possibly reflects impaired bone microarchitecture resulting from inflammation caused by AS, as observed in previous study (Klingberg et al. 2013). In addition, TBS excludes spine syndesmophytes from the analysis and don't cause false negative results.

However, this study has several limitations such as cross-sectional design and inclusion of postmenopausal females. There was a numerical difference in BMD, but not TBS between postmenopausal and premenopausal females, however, this was not statistically significant. This study has no control group and that is another limitation of the study. However, VF prevalence among normal population $<60$ years is reported less than $5 \%$ (Cosman et al. 2017) and thus we believe $17 \%$ prevalence of VF in similar age cohort with further comparison of subjects with and without VF is interesting to report regardless control group.

Possible limitation is absence of laboratory data such is vitamin D levels possibly correlating with occurrence of fractures. On the other side study strengths include representative number of subjects and use of IVA for VF assessment, which is in comparison to other similar studies (Kang et al. 2018a, Kang et al. 2018b, Richards et al. 2020), more usable in daily clinical routine due to its speed, small radiation and option to perform all bone examinations at same on same machine at one single place.

To conclude, assessment of fracture risk in 
secondary osteoporosis in routine practice, as mentioned above, has several limitations. TBS measurement may be useful simple non-invasive tool in many causes of secondary osteoporosis. Our data support the use of TBS, together with FN BMD to identify the AS patients at high fracture risk. Measurement of TBS can contribute to early detection of high-risk patient and subsequent prevention of bone loss can lead to decreased fracture risk in this relatively young and predominantly male population. Given that, use of highly degraded TBS $(\leq 1.23)$ threshold as defined by meta-analysis (McCloskey et al. 2016) could lead to detection of patient with VF or who is found to be at highest risk of future fracture and thus prevented with treatment or at least closely monitored. However, more studies with prospective design are needed to prove this hypothesis.

\section{Conflict of Interest}

There is no conflict of interest.

\section{Acknowledgement}

Grant support: VEGA 1/0378/21

\section{References}

ARENDS S, SPOORENBERG A, BRUYN GA, HOUTMAN PM, LEIJSMA MK, KALLENBERG CG, BROUWER E, VAN DER VEER E: The relation between bone mineral density, bone turnover markers, and vitamin D status in ankylosing spondylitis patients with active disease: a cross-sectional analysis. Osteoporos Int 22: 1431-1439, 2011. https://doi.org/10.1007/s00198-010-1338-7

COOPER C, CARBONE L, MICHET CJ, ATKINSON EJ, O'FALLON WM, MELTON LJ, 3RD: Fracture risk in patients with ankylosing spondylitis: a population based study. J Rheumatol 21: 1877-1882, 1994.

COSMAN F, KREGE JH, LOOKER AC, SCHOUSBOE JT, FAN B, SARAFRAZI ISFAHANI N, SHEPHERD JA, KROHN KD, STEIGER P, WILSON KE, GENANT HK: Spine fracture prevalence in a nationally representative sample of US women and men aged $\geq 40$ years: results from the National Health and Nutrition Examination Survey 2013-2014. Osteoporos Int 28: 1857-1866, 2017. https://doi.org/10.1007/s00198-017$\underline{3948-9}$

DELMAS PD, GENANT HK, CRANS GG, STOCK JL, WONG M, SIRIS E, ADACHI JD: Severity of prevalent vertebral fractures and the risk of subsequent vertebral and nonvertebral fractures: results from the MORE trial. Bone 33: 522-532, 2003. https://doi.org/10.1016/S8756-3282(03)00241-2

DEVOGELAER J-P, MALDAGUE B, MALGHEM J, DE DEUXCHAISNES CN: Appendicular and vertebral bone mass in ankylosing spondylitis. A comparison of plain radiographs with single- and dual-photon absorptiometry and with quantitative computed tomography. Arthritis Rheumatism 35: 1062-1067, 1992. https://doi.org/10.1002/art.1780350911

DONNELLY S, DOYLE DV, DENTON A, ROLFE I, MCCLOSKEY EV, SPECTOR TD: Bone mineral density and vertebral compression fracture rates in ankylosing spondylitis. Ann Rheum Dis 53: 117-121, 1994. https://doi.org/10.1136/ard.53.2.117

GARRETT S, JENKINSON T, KENNEDY LG, WHITELOCK H, GAISFORD P, CALIN A: A new approach to defining disease status in ankylosing spondylitis: the Bath Ankylosing Spondylitis Disease Activity Index. J Rheumatol 21: 2286-2291, 1994.

GENANT HK, JERGAS M, PALERMO L, NEVITT M, VALENTIN RS, BLACK D, CUMMINGS SR: Comparison of semiquantitative visual and quantitative morphometric assessment of prevalent and incident vertebral fractures in osteoporosis The Study of Osteoporotic Fractures Research Group. J Bone Miner Res 11: 984-996, 1996. https://doi.org/10.1002/jbmr.5650110716

GHOZLANI I, GHAZI M, NOUIJAI A, MOUNACH A, REZQI A, ACHEMLAL L, BEZZA A, EL MAGHRAOUI A: Prevalence and risk factors of osteoporosis and vertebral fractures in patients with ankylosing spondylitis. Bone 44: 772-776, 2009. https://doi.org/10.1016/j.bone.2008.12.028

JACKULIAK P, PAYER J: Osteoporosis, fractures, and diabetes. 2014: 820615, 2014. https://doi.org/10.1155/2014/820615

JUN JB, JOO KB, HER MY, KIM TH, BAE SC, YOO DH, KIM SK: Femoral bone mineral density is associated with vertebral fractures in patients with ankylosing spondylitis: a cross-sectional study. J Rheumatol 33: 1637-1641, 2006. 
KANG KY, CHUNG MK, KIM HN, HONG YS, JU JH, PARK SH: Severity of sacroiliitis and erythrocyte sedimentation rate are associated with a low trabecular bone score in young male patients with ankylosing spondylitis. J Rheumatol 45: 349-356, 2018a. https://doi.org/10.3899/jrheum.170079

KANG KY, KIM IJ, JUNG SM, KWOK SK, JU JH, PARK KS, HONG YS, PARK SH: Incidence and predictors of morphometric vertebral fractures in patients with ankylosing spondylitis. Arthritis Res Ther 16: R124, 2014. https://doi.org/10.1186/ar4581

KANG KY, KIM IJ, PARK SH, HONG YS: Associations between trabecular bone score and vertebral fractures in patients with axial spondyloarthritis. Rheumatology (Oxford) 57: 1033-1040, $2018 \mathrm{~b}$. https://doi.org/10.1093/rheumatology/key027

KARBERG K, ZOCHLING J, SIEPER J, FELSENBERG D, BRAUN J: Bone loss is detected more frequently in patients with ankylosing spondylitis with syndesmophytes. J Rheumatol 32: 1290-1298, 2005.

KILIC E, OZGOCMEN S: Bone mass in axial spondyloarthritis: A literature review. World J Orthop 6: 298-310, 2015. https://doi.org/10.5312/wjo.v6.i2.298

KILLINGER Z, GAJDAROVA L, KUZMA M, KRAJCOVICOVA A, BRAZDILOVA K, JACKULIAK P, PAYER J: Biologic treatment in comparison to methotrexate has positive effect on trabecular bone score in rheumatoid arthritis patients: 1-year follow-up. Acta Clin Belg 74: 121-125, 2019. https://doi.org/10.1080/17843286.2018.1512189

KLINGBERG E, GEIJER M, GÖTHLIN J, MELLSTRÖM D, LORENTZON M, HILME E, HEDBERG M, CARLSTEN H, FORSBLAD-D'ELIA H: Vertebral fractures in ankylosing spondylitis are associated with lower bone mineral density in both central and peripheral skeleton. J Rheumatol 39: 1987-1995, 2012. https://doi.org/10.3899/jrheum.120316

KLINGBERG E, LORENTZON M, GÖTHLIN J, MELLSTRÖM D, GEIJER M, OHLSSON C, ATKINSON EJ, KHOSLA S, CARLSTEN H, FORSBLAD-D'ELIA H: Bone microarchitecture in ankylosing spondylitis and the association with bone mineral density, fractures, and syndesmophytes. Arthritis Res Ther 15: R179, 2013. https://doi.org/10.1186/ar4368

KUZMA M, VANUGA P, BINKLEY N, SAGOVA I, PAVAI D, BLAZICEK P, KUZMOVA Z, JACKULIAK P, VANUGA A, KILLINGER Z, PAYER J: High serum fractalkine is associated with lower trabecular bone score in premenopausal women with graves' disease. Horm Metab Res 50: 609-614, 2018. https://doi.org/10.1055/a-0633-2814

KUŽMA M, VAŇUGA P, SÁGOVÁ I, PÁVAI D, JACKULIAK P, KILLINGER Z, BINKLEY NC, WINZENRIETH R, GENANT HK, PAYER J: Non-invasive DXA-derived bone structure assessment of acromegaly patients: a cross-sectional study. Eur J Endocrinol 180: 201-211, 2019. https://doi.org/10.1530/EJE-18-0881

LANGE U, TEICHMANN J, STRUNK J, MÜLLER-LADNER U, SCHMIDT KL: Association of 1.25 vitamin D3 deficiency, disease activity and low bone mass in ankylosing spondylitis. Osteoporos Int 16: 1999-2004, 2005. https://doi.org/10.1007/s00198-005-1990-5

LEIB ES, WINZENRIETH R: Bone status in glucocorticoid-treated men and women. Osteoporos Int 27: 39-48, 2016. https://doi.org/10.1007/s00198-015-3211-1

LESLIE WD, AUBRY-ROZIER B, LAMY O, HANS D: TBS (trabecular bone score) and diabetes-related fracture risk. J Clin Endocrinol Metab 98: 602-609, 2013. https://doi.org/10.1210/jc.2012-3118

MANDL P, NAVARRO-COMPÁN V, TERSLEV L, AEGERTER P, VAN DER HEIJDE D: EULAR recommendations for the use of imaging in the diagnosis and management of spondyloarthritis in clinical practice. Ann Rheum Dis 74: 1327-1339, 2015. https://doi.org/10.1136/annrheumdis-2014-206971

MCCLOSKEY EV, ODÉN A, HARVEY NC, LESLIE WD, HANS D, JOHANSSON H, BARKMANN R, BOUTROY S, BROWN J, CHAPURLAT R, ELDERS PJM, FUJTA Y, GLÜER CC, GOLTZMAN D, IKI M, KARLSSON M, KINDMARK A, KOTOWICZ M, KURUMATANI N, KWOK T, LAMY O, LEUNG J, LIPPUNER K, LJUNGGREN Ö, LORENTZON M, MELLSTRÖM D, MERLIJN T, OEI L, OHLSSON C, PASCO JA, RIVADENEIRA F, ROSENGREN B, SORNAY-RENDU E, SZULC P, TAMAKI J, KANIS JA: A meta-analysis of trabecular bone score in fracture risk prediction and its relationship to FRAX. J Bone Miner Res 31: 940-948, 2016. https://doi.org/10.1002/jbmr.2734 
MITRA D, ELVINS DM, SPEDEN DJ, COLLINS AJ: The prevalence of vertebral fractures in mild ankylosing spondylitis and their relationship to bone mineral density. Rheumatology (Oxford) 39: 85-89, 2000. https://doi.org/10.1093/rheumatology/39.1.85

MONTALA N, JUANOLA X, COLLANTES E, MUÑOZ-GOMARIZ E, GONZALEZ C, GRATACOS J, ZARCO P, FERNANDEZ SUEIRO JL, MULERO J, TORRE-ALONSO JC, BATLLE E, CARMONA L: Prevalence of vertebral fractures by semiautomated morphometry in patients with ankylosing spondylitis. J Rheumatol 38 : 893-897, 2011. https://doi.org/10.3899/jrheum.100851

MUÑOZ-ORTEGO J, VESTERGAARD P, RUBIO JB, WORDSWORTH P, JUDGE A, JAVAID MK, ARDEN NK, COOPER C, DÍEZ-PÉREZ A, PRIETO-ALHAMBRA D: Ankylosing spondylitis is associated with an increased risk of vertebral and nonvertebral clinical fractures: a population-based cohort study. J Bone Miner Res 29: 1770-1776, 2014. https://doi.org/10.1002/jbmr.2217

RICHARDS C, HANS D, LESLIE WD: Trabecular Bone Score (TBS) predicts fracture in ankylosing spondylitis: The Manitoba BMD Registry. J Clin Densitom: 2020. https://doi.org/10.1016/j.jocd.2020.01.003

ULU MA, BATMAZ İ, DILEK B, ÇEVIK R: Prevalence of osteoporosis and vertebral fractures and related factors in patients with ankylosing spondylitis. Chin Med J (Engl) 127: 2740-2747, 2014.

VOSSE D, LANDEWÉ R, VAN DER HEIJDE D, VAN DER LINDEN S, VAN STAA TP, GEUSENS P: Ankylosing spondylitis and the risk of fracture: results from a large primary care-based nested case-control study. Ann Rheum Dis 68: 1839-1842, 2009. https://doi.org/10.1136/ard.2008.100503

VOSSE D, VAN DER HEIJDE D, LANDEWÉ R, GEUSENS P, MIELANTS H, DOUGADOS M, VAN DER LINDEN S: Determinants of hyperkyphosis in patients with ankylosing spondylitis. Ann Rheum Dis 65: 770-774, 2006. https://doi.org/10.1136/ard.2005.044081 